\title{
Incidence and risk factors of post-operative cognitive decline after ablation for atrial fibrillation
}

Jing Zhang ${ }^{1,2}$, Shi-Jun Xia ${ }^{1}$, Xin Du' ${ }^{1}$, Chao Jiang ${ }^{1}$, Yi-Wei Lai ${ }^{1}$, Yu-Feng Wang ${ }^{1}$, Zhao-Xu Jia ${ }^{1}$, Liu He ${ }^{1}$, Ri-Bo Tang ${ }^{1}$, Jian-Zeng Dong ${ }^{1}$ and Chang-Sheng $\mathrm{Ma}^{1 *}$ (D)

\begin{abstract}
Background: Catheter ablation is widely used in atrial fibrillation (AF) management. In this study, we are aimed to investigate the incidence of postprocedural cognitive decline in a larger population undergoing AF ablation under local anesthesia, and to evaluate the associated risk factors.

Methods: This study included 287 patients with normal cognitive functions, with 190 ablated AF patients (study group) and $97 \mathrm{AF}$ patients who are awaiting ablation (practice group). We assessed the neuropsychological function of each patient for twice (study group: $24 \mathrm{~h}$ prior to ablation and $48 \mathrm{~h}$ post ablation; practice group: on the day of inclusion and $72 \mathrm{~h}$ later but before ablation). The reliable change index was used to analyze the neuropsychological testing scores and to identify postoperative cognitive dysfunction (POCD) at $48 \mathrm{~h}$ post procedure. Patients in the study group accepting a 6-month follow up were given an extra cognitive assessment.

Results: Among the ablated AF patients, 13.7\% (26/190) had POCD at $48 \mathrm{~h}$ after the ablation procedure. Multivariable analysis revealed that, a minimum intraoperative activated clotting time (ACT) $<300$ s (OR 3.82, 95\% Cl 1.48-9.96, $P=0.006)$ and not taking oral anticoagulants within one month prior to ablation(OR $10.35,95 \% \mathrm{Cl} 3.54-30.27$, $P<0.001$ ) were significantly related to POCD at $48 \mathrm{~h}$ post-ablation. In 172 patients of the study group accepting a 6-month follow up, there were 23 patients with POCD at $48 \mathrm{~h}$ post-ablation and 149 patients without POCD. The global cognitive scores were decreased in $48 \mathrm{~h}$ post-operation tests $(0 \pm 1 \mathrm{vs}-0.15 \pm 1.10, P<0.001)$ and improved significantly at 6 months post-operation ( $0 \pm 1$ vs $0.43 \pm 0.92, P<0.001)$. In the 23 patients with POCD at $48 \mathrm{~h}$ after the procedure, global cognitive performance at 6 months was not significantly different compared with that at baseline $(-0.05 \pm 1.25$ vs $-0.19 \pm 1.33, P=0.32)$, while 13 of them had higher scores than baseline level.

Conclusions: Incident of POCD after ablation procedures is high in the short term. Inadequate periprocedural anticoagulation are possible risk factors. However, most POCD are reversible at 6 months, and a general improvement was observed in cognitive function at 6 months after ablation.
\end{abstract}

*Correspondence: changshengm1@163.com

${ }^{1}$ Department of Cardiology, Beijing Anzhen Hospital, Capital Medical University, National Clinical Research Center for Cardiovascular Diseases,

No. 2 Anzhen Road, Chaoyang District, Beijing 100029, China

Full list of author information is available at the end of the article

\section{Introduction}

Atrial fibrillation (AF) ablation has been adopted as a first-line therapy in symptom control and the improvement of patients' quality of life (QoL) [1-3]. However, subclinical cerebral ischemia is common during AF ablation [4], which may result in postprocedural cognitive impairment. Studies on the association between AF ablation and cognitive impairment are limited. The 
incidence of postoperative cognitive dysfunction (POCD) is reported to be as high as $28 \%$ in $48 \mathrm{~h}$ after AF ablation, and it seems part of them are reversible [5]. However, current studies are inconsistent in terms of the association between AF ablation and POCD [6-9]. Additionally, the ablation procedures in most current studies were carried out under general anesthesia. Whether the POCD is associated with general anesthesia or AF ablation per se, and if associations exist with other factors were still unknown.

In this study, we aim to describe the incidence of postprocedural cognitive decline in a larger population undergoing AF ablation under local anesthesia, and to evaluate the associated risk factors.

\section{Methods}

\section{Study population}

From March 2017 to August 2017, AF patients in the AF ablation waiting list of Beijing Anzhen Hospital were enrolled for primary cognitive screening. Patients over 60 years of age with normal cognitive functions were included and further randomly divided into ablated AF patients (study group) and AF patients who are awaiting ablation (practice group). Exclusion criteria included preexisting neurological or clinically evident neurovascular disease, significant pre-morbid depression and/or anxiety, anticipated difficulty with neurocognitive assessment (e.g., deafness, language difficulties), and with history of cardiopulmonary bypass surgery.

In the study group, cognitive assessment was administered at $24 \mathrm{~h}$ prior to ablation and $48 \mathrm{~h}$ after the ablation procedure respectively. The practice group was set up to determine the practice effect of cognitive tests resulted from repeated testing, two consecutive cognitive assessment were administered to them with a 72-h interval before the ablation. All patients provided a written informed consent for both the baseline and post-procedural cognitive assessments.

In patients of the study group consenting to accept an extra 6-month cognitive assessment at enrollment, practice effect was not considered in 6-month cognitive assessment, for previous study have reported similar test results between the baseline and 3-month assessment in non-ablated AF patients [10].

\section{Neuropsychological testing}

A trained interviewer administered neuropsychological testing to all included patients. A well-established formal testing battery consisting of nine tests were used, which is based on the Canadian Study of Health and Aging [1115] (Appendix Table 4).
The interviewer recorded both the number of correct answers and the time taken to complete the tests. To reduce the potential influence by other factors, parallel neuropsychological testing was conducted in the same room, by the same interviewer, and at the same time of the day for each recruited patient.

Visual analog scales were also utilized to assess the presence of mood disorder levels which may influence the scores on neuropsychological tests. Patients were asked to estimate their current levels of depression and anxiety by marking a line standardized to $10 \mathrm{~cm}$ in length [13].

\section{Definition of POCD at $48 \mathrm{~h}$ after ablation}

The reliable change index (RCI) was used to analyze the neuropsychological testing scores and to identify POCD $[15,16]$.The details of the RCI calculation are listed as follows:

For all the patients in both the study group and the practice group, the initial testing raw score (X1) was subtracted from the final testing raw score (X2) to produce a $\Delta \mathrm{X}$ for each task except the timed tasks. We subtracted the final testing raw score (X2) from the initial testing raw score (X1) to calculate a $\Delta \mathrm{X}$ for the timed tasks (Trail Making Task, Parts A and B, and Grooved Pegboard Test, Dominant and Non-dominant Hands).

To eliminate any learning and practice effects, we subtracted the mean difference [Mean $(\Delta \mathrm{Xp})]$ of the practice group from the change in study group patient's testing scores $(\Delta \mathrm{X})$ and then divided it by the SD of the change in test results of the practice group $[\mathrm{SD}(\Delta \mathrm{Xp})]$, controlling for the expected variability, to obtain the final z-score for every test.

$$
\begin{aligned}
& \mathrm{Z} \text {-score }=[(\mathrm{X} 2-\mathrm{X} 1)-\mathrm{Mean}(\Delta \mathrm{Xp})] / \mathrm{SD}(\Delta \mathrm{Xp}) \text { (for every } \\
& \text { test except the timed tasks) } \\
& \mathrm{Z} \text {-score }=[(\mathrm{X} 1-\mathrm{X} 2)-\mathrm{Mean}(\Delta \mathrm{Xp})] / \mathrm{SD}(\Delta \mathrm{Xp}) \quad(\text { for the } \\
& \text { timed tasks })
\end{aligned}
$$

A combined test score $\left(\sum \mathrm{Z}_{\text {combined }}\right)$ was created by using the sum of $\mathrm{z}$-scores for each test $\left(\sum \mathrm{Z} 1,2,3 \ldots 9\right)$ divided by the $\mathrm{SD}$ of this summation in the practice group (SD $\left.\left[\sum \mathrm{Z}_{\text {practice }} 1,2,3 \ldots 9\right]\right)$.

$$
\sum Z_{\text {combined }}=\sum Z 1,2,3 \ldots 9 / S D\left(\sum Z_{\text {practice }} 1,2,3 \ldots 9\right)
$$

We defined the presence of POCD when the $\mathrm{z}$-score $<-1.96$ on $\geq 2$ tests, or the combined $\mathrm{z}$-score $<-1.96[15,16]$. 


\section{Cognitive assessment in 6-month follow-up}

Comparisons of neuropsychological outcomes were made among pre-operation, and $48 \mathrm{~h}$ and 6 months postoperation. The mean difference between cognitive assessments in the practice group was defined as practice effect and was subtracted from raw scores of $48 \mathrm{~h}$ postoperative tests in the study group. All test results were transformed to $\mathrm{z}$ scores. A global cognitive score was created by averaging the $\mathrm{z}$ scores of each subtest and standardizing them [17]. Absolute test scores were reversed for timed tasks, hence higher $\mathrm{z}$ scores always represent better test performance.

\section{Perioperative anticoagulation management}

Transesophageal echocardiography (TEE) was performed in every patient to rule out the left atrium or atrial appendage thrombus before the $\mathrm{AF}$ ablation procedure.

During admission, for patients on warfarin, a nonstop strategy was used (i.e., no low-molecular-weight heparin LMWH bridging) if the international normalized ratio (INR) value was between 2.0 and 3.0. If the patient's INR value was below 2.0, bridging with LMWH while titrating warfarin was conducted until a therapeutic INR was obtained. If the INR value was above 3.0, we titrated the warfarin dose by stopping or reducing the warfarin dose under close monitoring. For patients on new oral anticoagulants (NOAC), we stopped using NOAC after admission and bridged with full-dose LMWH and reinitiated NOAC at six hours after the ablation procedure. For those not on warfarin or NOAC at admission, fulldose LMWH was administered, and post-procedure oral anticoagulation use was a shared decision between doctors and patients. All patients were treated with anticoagulants for at least 3 months postoperatively, and then at 3 months, patients with a CHA2DS2-VAS score $>=2$ were encouraged to continue using oral anticoagulation.

During the procedure, ACT was measured every 30 min to maintain an ACT level above $300 \mathrm{~s}$.

\section{AF ablation procedure}

After overnight fasting, the patients received AF ablation procedures under conscious sedation with fentanyl. Circumferential pulmonary vein isolation was applied for the patients with paroxysmal atrial fibrillation (PAF) $[18,19]$ while a fixed '2C3L' approach for patients with non-paroxysmal AF [20] were applied, guided by a threedimensional electroanatomic mapping system (CARTO, Biosense-Webster, Inc.). The '2C3L' strategy is a fixed approach for ablation of persistent AF, which consists of bilateral circumferential pulmonary vein antrum isolation ('2C') and three linear ablation sets ('3L').Linear ablation is empirically applied across the mitral isthmus, the left atrial roof, and the cavo-tricuspid isthmus. Ablation energy was delivered with a maximum power of 30 to $35 \mathrm{~W}$ with continuous heparinized saline flow at a rate of $17 \mathrm{~mL} / \mathrm{min}$.

\section{Statistical analysis}

The data were reported as the mean \pm standard deviation (SD) for continuous variables and frequency (\%) for categorical variables, while the Student's t-test and chi-squared test were deployed to assess the differences between the groups. Univariate logistic regression analysis was performed to assess the association of each variable with POCD. The variables with a $P$ value $<0.05$ in the univariate analysis and of clinical importance were then included in the multivariate logistic regression analysis, including the $\mathrm{CHA}_{2} \mathrm{DS}_{2}$-VASc score $(<2$ for males, $<3$ for females), the minimum intraoperative ACT $(<300 \mathrm{~s})$, and non-administration of oral anticoagulants within the one month prior to the ablation. Probability values less than 0.05 were considered as significant difference. All analyses were conducted using SPSS version 22.0 for Windows.

\section{Results \\ Baseline characteristics}

From March 2017 to August 2017, 625 AF patients in the AF ablation waiting list of Beijing Anzhen Hospital were enrolled for primary cognitive screening. After excluding 238 patients under 60 years of age, 29 patients with a history of stroke, 2 patients who suffered from severe neurological/psychiatric disorders, 6 patients with a history of depression/anxiety, 7 patients who suffered from anticipated difficulty in neurocognitive assessment (e.g., deafness, language difficulties), 4 patients who took surgeries under cardiopulmonary bypass grafting, and another 39 patients with cognitive impairment assessed by the MiniMental State Examination (MMSE) test prior to the ablation procedure, 300 cognitively normal patients were included in the study.

Among them, 99 patients were randomly assigned to the practice group to determine the practice effect of cognitive tests resulted from repeated testing, two consecutive cognitive assessment were administered to them with a 72-h interval before the ablation. For 201 patients assigned to the study group, cognitive assessment was administered at $24 \mathrm{~h}$ prior to ablation and $48 \mathrm{~h}$ after the ablation procedure respectively. Thirteen patients did 


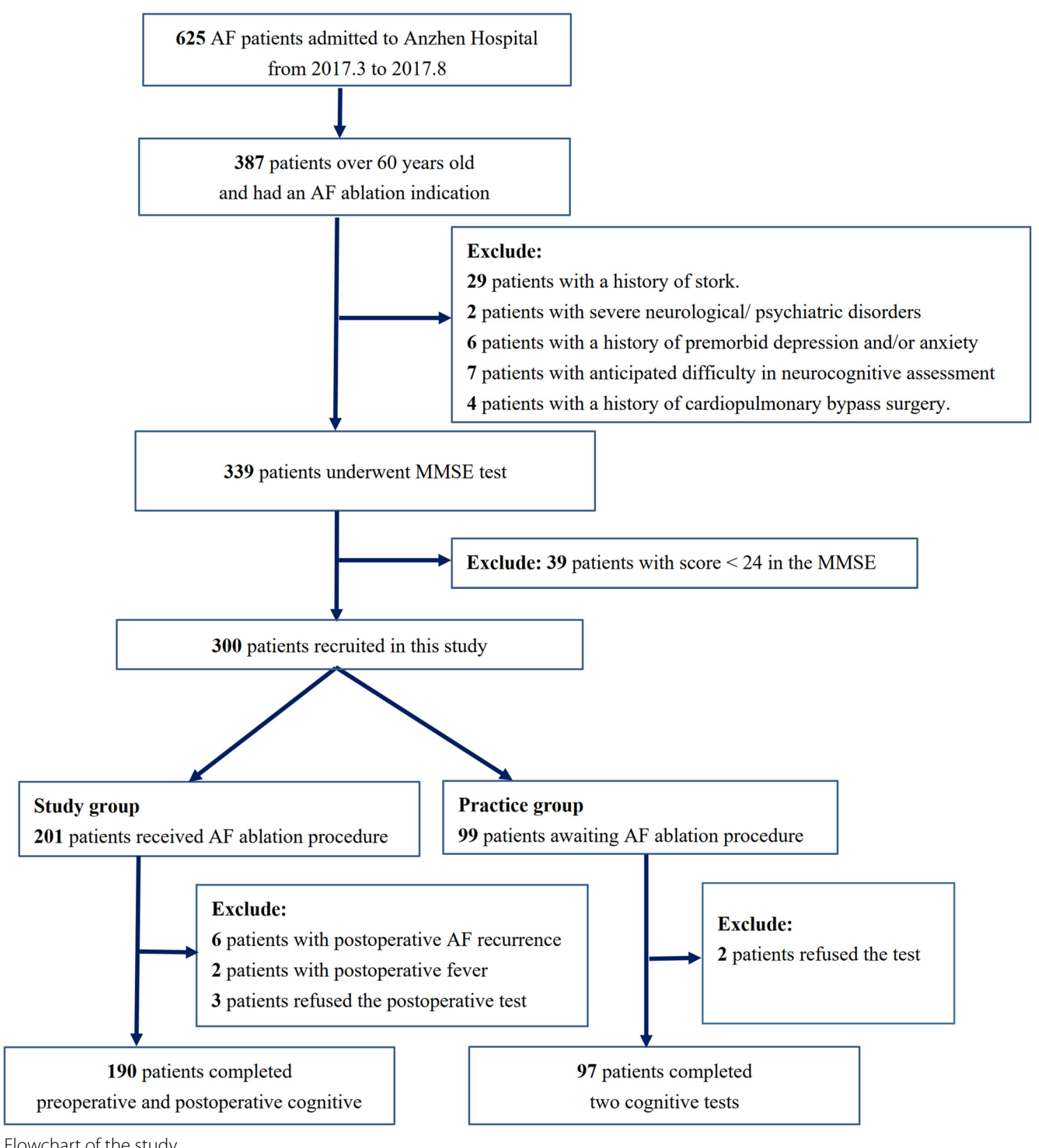

not complete the postoperative tests because of postoperative AF recurrence (6 patients), postoperative fever (2 patients), and withdrawal of consent (5 patients). Finally, data from 190 patients in the study group and 97 patients in the practice group were included in the current analysis (Fig. 1).

The characteristics of 190 patients in the study group and 97 patients in the practice group were listed in Table 1. The demographic characteristics of the two groups were similar with respect to male gender ( $59.5 \%$ vs $54.6 \%, P=0.43$ ), age
(66.6 \pm 5.4 vs $67.5 \pm 5.0, P=0.11$ ), high educational level ( $30 \%$ vs $32 \%, P=0.73)$, and PAF ( $68.9 \%$ vs $64.9 \%, P=0.49)$. No significant differences in the prevalence of comorbidities and current medication were observed between the two groups.

\section{Perioperative anticoagulant strategies and procedural characteristics}

In this study, all the ablated AF patients received TEE in admission. No left atrium or left appendage thrombi were found. 
Table 1 Baseline characteristics

\begin{tabular}{llll}
\hline Variable & $\begin{array}{l}\text { Study group } \\
(\mathbf{n}=\mathbf{1 9 0 )}\end{array}$ & $\begin{array}{l}\text { Practice } \\
\text { group } \\
\mathbf{( n = 9 7 )}\end{array}$ & $\boldsymbol{P}$ value \\
\hline Age (years) & $66.6 \pm 5.4$ & $67.7 \pm 5.0$ & 0.11 \\
Male & $113(59.5)$ & $53(54.6)$ & 0.43 \\
College and above & $57(30.0)$ & $31(32.0)$ & 0.73 \\
Paroxysmal atrial fibrillation & $131(68.9)$ & $63(64.9)$ & 0.49 \\
Diabetes & $33(17.4)$ & $15(15.5)$ & 0.68 \\
Hypertension & $122(64.2)$ & $57(58.8)$ & 0.37 \\
Dyslipidemia & $41(21.6)$ & $25(25.8)$ & 0.42 \\
Coronary heart disease & $30(15.8)$ & $13(13.4)$ & 0.59 \\
Heart failure & $10(5.3)$ & $4(4.1)$ & 0.78 \\
Level of anxiety\# & $3.8 \pm 1.3$ & $3.6 \pm 0.7$ & 0.14 \\
Level of depression\# & $2.7 \pm 1.3$ & $2.7 \pm 1.1$ & 0.72 \\
Smoker & $33(17.4)$ & $14(14.4)$ & 0.52 \\
CHA ${ }_{2}$ DS ${ }_{2}$-VASc score $(<2$ for & $89(46.8)$ & $40(41.2)$ & 0.38 \\
$\quad$ males, $<3$ for females) & & & \\
Oral anticoagulants & $116(61.1)$ & $56(57.7)$ & 0.59 \\
Antiplatelet & $19(10.0)$ & $12(12.4)$ & 0.54 \\
ACEl/ARB & $57(30.0)$ & $34(35.1)$ & 0.38 \\
Statins & $91(47.9)$ & $40(41.2)$ & 0.28 \\
\hline
\end{tabular}

Values are presented as the mean \pm SD or $\mathrm{n}(\%)$

\# Level of anxiety and depression assessed by visual analog scales

A total of 116 ablated patients were on oral anticoagulants for at least one month before the procedure. Among them, 27 patients who took warfarin orally before admission were treated with a nonstop strategy while 89 patients who took NOACs before admission were given LMWH bridging. All the other 74 ablated patients not on anticoagulants within one month before the procedure were given LMWH bridging.

Successful pulmonary vein isolation was achieved in all ablated patients. Sixty-two patients (32.6\%) underwent adjuvant linear ablation. None of the patient developed a transient ischemic attack/stroke or had other perioperative clinical embolic events.

\section{Incidence of POCD at $\mathbf{4 8} \mathrm{h}$ after ablation}

Among the ablated patients, 26 out of 190 patients (13.7\%) satisfied the definition of POCD at $48 \mathrm{~h}$ after ablation. Cognitive impairment was detected across the entire range of tests. The tests with the most prominent decrease in scores were the CERAD-I and CERAD-D (memory), the Trail Making Test A and B (executive functioning), and combined score ( $\mathrm{Z})$. The incidence of cognitive deficits ( $\mathrm{z}$-score was less than -1.96$)$ were significantly higher in the study group in CERAD-I $(15.8 \%$
Table 2 Impaired performance on neuropsychological tests in study group and practice group at $48 \mathrm{~h}$ after ablation

\begin{tabular}{llll}
\hline Variable & $\begin{array}{l}\text { Study } \\
\text { group } \\
(\mathbf{n}=\mathbf{1 9 0 )}\end{array}$ & $\begin{array}{l}\text { Practice } \\
\text { group } \\
\mathbf{( n = 9 7 )}\end{array}$ & P value \\
\hline CERAD-I & $30(15.8)$ & $3(3.1)$ & $0.001^{*}$ \\
CERAD-D & $25(13.2)$ & $4(4.1)$ & $0.02^{*}$ \\
Trail A (s) & $22(11.4)$ & $2(2.1)$ & $0.01^{*}$ \\
Trail B (s) & $17(8.9)$ & $2(2.1)$ & $0.03^{*}$ \\
Digit symbol substitution & $6(3.2)$ & $1(1.0)$ & 0.43 \\
Controlled oral word association & $8(4.2)$ & $3(3.1)$ & 0.76 \\
CERAD Semantic Fluency & $6(3.2)$ & $4(4.1)$ & 0.74 \\
Grooved Pegboard Test-D (s) & $6(3.2)$ & $0(0)$ & 0.10 \\
Grooved Pegboard Tes-N (s) & $6(3.2)$ & $0(0)$ & 0.10 \\
Combined Score (Z) & $19(10.0)$ & $2(2.1)$ & $0.02^{*}$ \\
\hline
\end{tabular}

Values are presented as $\mathrm{n}(\%)$

The asterisk indicates statistical significance

vs $3.1 \%, P=0.001)$, CERAD-D $(13.2 \%$ vs $4.1 \%, P=0.02)$, Trail-A $(11.4 \%$ vs $2.1 \%, P=0.01)$, Trail-B $(8.9 \%$ vs $2.1 \%$, $P=0.03)$, and combined $\mathrm{z}$ score $(10.0 \%$ vs $2.1 \%, P=0.02)$ (Table 2). The global cognitive scores at baseline and $48 \mathrm{~h}$ post-ablation for the study group and the practice group were shown in Appendix Fig. 4.

\section{Factors associated with POCD at $\mathbf{4 8} \mathrm{h}$ after ablation}

The variables included in the univariate logistic regression were age, sex, education, AF type, comorbidities (i.e., diabetes, hypertension, dyslipidemia, coronary artery disease, heart failure), smoking status, medication use (i.e., oral antiplatelet drugs, ACEI/ARB, statins), $\mathrm{CHA}_{2} \mathrm{DS}_{2}$-VASc score, levels of depression and anxiety, and procedure-related factors (Table 3 ). The minimum intraoperative ACT of $<300 \mathrm{~s}$ and not taking an oral anticoagulant within one month before the ablation procedure were found to be significantly associated with POCD occurrence, which were then included in the multivariate logistic regression analysis.

In the multivariate adjustment, the minimum intraoperative $\mathrm{ACT}<300$ s (OR 3.82, 95\% CI 1.48-9.96; $P=0.006)$ and not taking oral anticoagulant within one month before the ablation procedure (OR 10.35, 95\% CI $3.54-30.27 ; P<0.001)$ were significantly associated with POCD occurrence, while $\mathrm{CHA}_{2} \mathrm{DS}_{2}$-VASc $(<2$ for males, $<3$ for females) was not related to POCD (OR 0.95, 95\% CI $0.38-2.39, P=0.91)$. The univariable and multivariable adjustment for factors associated with POCD at $48 \mathrm{~h}$ after ablation in the study group were shown in Table 3. 
Table 3 Univariable and multivariable adjustment for factors associated with POCD at $48 \mathrm{~h}$ after ablation in the study group

\begin{tabular}{|c|c|c|c|c|c|c|c|c|}
\hline \multirow[t]{2}{*}{ Variable } & \multirow{2}{*}{$\begin{array}{l}\text { Patients } \\
\text { with POCD } \\
(n=26)\end{array}$} & \multirow{2}{*}{$\begin{array}{l}\text { Patients } \\
\text { without POCD } \\
\text { ( } n=164)\end{array}$} & \multicolumn{3}{|c|}{ Univariable adjustment } & \multicolumn{3}{|c|}{ Multivariable adjustment } \\
\hline & & & OR & $95 \% \mathrm{Cl}$ & $P$ value & OR & $95 \% \mathrm{Cl}$ & $P$ value \\
\hline Age (years) & $67.7 \pm 6.3$ & $66.4 \pm 5.3$ & 1.04 & $0.97-1.12$ & 0.26 & - & - & - \\
\hline Male & $12(46.2)$ & $101(61.6)$ & 1.87 & $0.81-4.30$ & 0.14 & - & - & - \\
\hline College and above & $5(19.2)$ & $52(31.7)$ & 0.51 & $0.18-1.44$ & 0.20 & - & - & - \\
\hline Paroxysmal atrial fibrillation & $17(65.4)$ & $114(69.5)$ & 1.21 & $0.50-2.89$ & 0.67 & - & - & - \\
\hline Diabetes & $3(11.5)$ & $30(18.3)$ & 0.58 & $0.16-2.07$ & 0.40 & - & - & - \\
\hline Hypertension & $16(61.5)$ & $106(64.6)$ & 0.88 & $0.37-2.05$ & 0.76 & - & - & - \\
\hline Dyslipidemia & $4(15.4)$ & $37(22.6)$ & 0.62 & $0.20-1.93$ & 0.41 & - & - & - \\
\hline Coronary artery disease & $6(23.1)$ & $24(14.6)$ & 1.75 & $0.64-4.80$ & 0.28 & - & - & - \\
\hline Heart failure & $3(11.5)$ & $7(4.3)$ & 2.96 & $0.71-12.12$ & 0.14 & - & - & - \\
\hline Smoker & $4(15.4)$ & $29(17.7)$ & 0.85 & $0.27-2.64$ & 0.77 & - & - & - \\
\hline Oral antiplatelet drugs & $4(15.4)$ & $15(9.1)$ & 1.81 & $0.55-5.94$ & 0.33 & - & - & - \\
\hline ACEI/ARB & $10(38.5)$ & $47(28.7)$ & 1.56 & $0.66-3.68$ & 0.31 & - & - & - \\
\hline Statins & $13(50.0)$ & $78(47.6)$ & 1.10 & $0.48-2.52$ & 0.82 & - & - & - \\
\hline $\mathrm{CHA}_{2} \mathrm{DS}_{2}$-VASc score ( $<2$ for males, $<3$ for females) & $11(42.3)$ & $78(47.6)$ & 0.81 & $0.35-1.87$ & 0.62 & 0.95 & $0.38-2.39$ & 0.91 \\
\hline Level of depression & $2.6 \pm 1.4$ & $2.7 \pm 1.2$ & 0.93 & $0.66-1.30$ & 0.67 & - & - & - \\
\hline Level of anxiety & $3.7 \pm 1.6$ & $3.8 \pm 1.3$ & 0.97 & $0.70-1.34$ & 0.85 & - & - & - \\
\hline Intraoperative hypotension & $0(0.0)$ & $2(1.2)$ & 0.00 & 0.00 & 1.00 & - & - & - \\
\hline Direct current cardioversion & $7(26.9)$ & $34(20.7)$ & 1.41 & $0.55-3.63$ & 0.48 & - & - & - \\
\hline Minimum intraoperative $\mathrm{ACT}<300 \mathrm{~s}$ & $12(46.2)$ & $38(23.2)$ & 2.84 & $1.21-6.66$ & $0.02^{*}$ & 3.82 & $1.48-9.96$ & $0.006^{*}$ \\
\hline Left atrial access time (min) & $125.6 \pm 32.6$ & $120.2 \pm 38.1$ & 1.00 & $0.99-1.01$ & 0.50 & - & - & - \\
\hline Radiofrequency duration (min) & $83.1 \pm 31.0$ & $80.0 \pm 34.1$ & 1.00 & $0.99-1.02$ & 0.66 & - & - & - \\
\hline Fentanyl dosage $(\mu \mathrm{g})$ & $161.3 \pm 45.3$ & $160.5 \pm 48.4$ & 1.00 & $0.99-1.01$ & 0.93 & - & - & - \\
\hline $\begin{array}{l}\text { Not on oral anticoagulant within 1-month prior to } \\
\text { ablation }\end{array}$ & $21(80.8)$ & $53(32.3)$ & 8.80 & $3.14-24.6$ & $<0.001^{*}$ & 10.35 & $3.54-30.27$ & $<0.001^{*}$ \\
\hline No oral anticoagulants interruption & $3(11.5)$ & $24(14.6)$ & 0.76 & $0.21-2.73$ & 0.68 & - & - & - \\
\hline
\end{tabular}

Values are presented as the mean \pm SD or $\mathrm{n}(\%)$

$\mathrm{OR}$, odds ratio; $\mathrm{Cl}$, confidence interval; the asterisk indicates statistical significance

\section{Cognitive outcomes in 6-month follow-up}

172 patients in the study group accepted a 6-month follow up for an extra cognitive assessment, including 23 patients with POCD at $48 \mathrm{~h}$ post-ablation and 149 patients without POCD. In these 172 patients, the global cognitive scores decreased in $48 \mathrm{~h}$ post-operation tests $(0 \pm 1$ vs $-0.15 \pm 1.10, P<0.001)$ and improved significantly at 6 months post-operation $(0 \pm 1$ vs $0.43 \pm 0.92$, $P<0.001)$. Cognitive scores at 6 months improved significantly in memory: CERAD-I $(0 \pm 1$ vs $0.30 \pm 0.90$, $P<0.001)$, CERAD-D $(0 \pm 1$ vs $0.25 \pm 0.99, P<0.001)$; in executive function: Trail-A $(0 \pm 1$ vs $0.16 \pm 0.80$, $P<0.001)$, Trail-B $(0 \pm 1$ vs $0.33 \pm 0.84, P<0.001)$; in working memory and processing function: Digit Symbol Substitution Test $(0 \pm 1$ vs $0.21 \pm 1.01, P<0.001)$, in verbal fluency test: Controlled Oral Word Association
Test ( $0 \pm 1$ vs $0.25 \pm 0.97, P<0.001)$, and in visual-motor coordination: Grooved-D ( $0 \pm 1$ vs $0.32 \pm 0.69, P<0.001)$, Grooved-N tests $(0 \pm 1$ vs $0.22 \pm 0.69, P<0.001)$. Detailed analysis of changes in global cognitive scores and individual tested $\mathrm{Z}$ scores from baseline to 6 months follow-up were shown in Fig. 2.

In the 23 patients with POCD at $48 \mathrm{~h}$ after the procedure, global cognitive performance at 6 months has no significant difference to that at baseline $(-0.05 \pm 1.25$ vs $-0.19 \pm 1.33, P=0.32$ ), and 13 of them had higher scores than baseline level. The trajectories of global cognitive scores in 23 patients with POCD at $48 \mathrm{~h}$ after the procedure are shown in Fig. 3a. The comparison between the POCD group and the non POCD group at baseline, $48 \mathrm{~h}$ post-ablation, 6 months post-ablation were shown in Fig. 3b. 


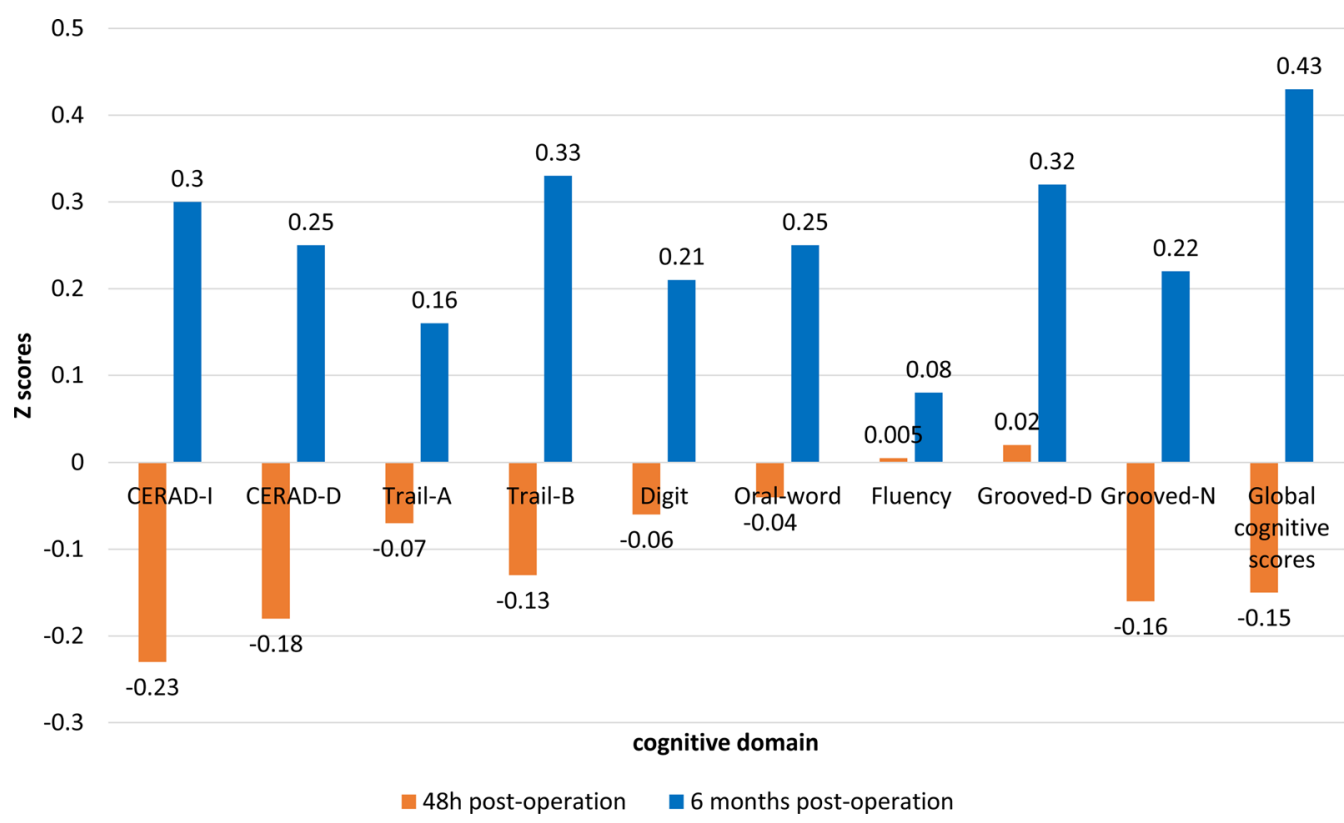

Fig. 2 Changes in individual Z scores and global cognitive scores. The mean value of the scores of the baseline after standardization is 0 . CERAD-l: CERAD Auditory-Verbal Learning Test-Immediate; CERAD-D: CERAD Auditory-Verbal Learning Test-Delayed; Trail-A: Trail Making Task Part A; Trail-B: Trail Making Task Part B; Digit: Digit Symbol Substitution Test; Oral-word: Controlled Oral Word Association Test; Fluency: CERAD Semantic Fluency Test; Grooved-D: Grooved Pegboard Test (Dominant Hand); Grooved-N: Grooved Pegboard Test (Non-dominant Hand)

\section{Discussion}

The main findings of this study were that $13.7 \%(26 / 190)$ of patients undergoing AF ablation had postoperative cognitive decline at $48 \mathrm{~h}$ after AF ablation, even under local anesthesia, which was associated with poor anticoagulation before and during the operation procedure. The memory and executive function were the most commonly affected cognitive domains. However, this cognitive impairment seemed to be only temporary. In overall population, AF ablation might be associated with cognition improvement after 6 months post-operation.

As previously reported, the incidence of subclinical post-procedural cognitive impairment was significantly higher at $48 \mathrm{~h}$ after the procedure under general anesthesia [5]. Similarity, POCD was observed in the present study but with a lower 48-h incidence (13.7\%), indicating general anesthesia may affect patients' cognitive function shortly after the operation.

Besides anesthesia, the underlying mechanism for cognitive impairment caused by ablation itself remains controversial. It has been shown that "subclinical" or "silent" strokes contribute to memory impairment and cognitive decline [21-23]. AF patients have a higher risk of silent brain lesions and cognitive impairment [24]. A previous study reported a high incidence of AF ablation-related subclinical intracranial embolic events, which was estimated at $50 \%$, depending on the specific MRI protocols used to identify acute embolic lesions [25]. In post-AF ablation patients, adverse neuropsychological changes in patients' verbal memory, conjoined with ischemic brain injury on DWI have been observed [9]. Accordingly, we found that the quality of peri-procedural anticoagulation seems to be crucial to POCD. On the contrary, it has also been showed that no neuropsychological effect was found from these incident brain lesions in 16 of 37 patients undergoing AF ablation [7]. However, in this study, patients' post-operative cognitive status was only assessed 6 months after ablation, when many of brain lesions have ceased to persist. Therefore, a study with a larger sample size and more frequent cognitive monitor is expected in the future.

Generally, the AF ablation procedure might induce thromboembolic events through several potential mechanisms. First, the catheter and sheath maneuver, as well as endothelial ablation in the left atrium, are prone to thrombus formation. Second, AF ablation itself induces systemic coagulation system activation and may cause left atrial diastolic dysfunction, further increasing thromboembolism risk [26]. Third, perioperative anticoagulation interruption and bridging therapy placed atrial fibrillation patients in an unstable anticoagulation state, thus increasing the risk for brain infarction and microbleeds, which has also attributed to POCD [27, 28]. Aside from the 


\section{A}

3

- case 1

- case 2

2

- case 3

-case 4

-v-case 5

_case 6

1

—case 7

$\rightarrow$ case 8

$\longrightarrow$ case 9

ญั

ญั 0

¿

竞

능

엉

은

$-3$

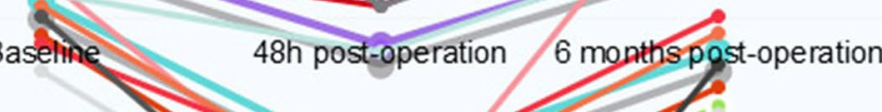

$\longrightarrow$ case 10

$\longrightarrow$ case 11

$\longrightarrow$ case 12

$\longrightarrow$ case 13

$\Longrightarrow$ case 14

- case 15

- case 16

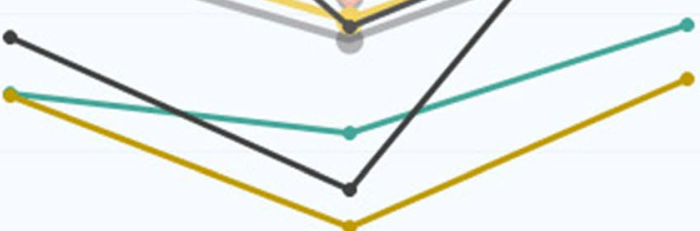

—case 17

- case 18

$\longrightarrow$ case 19

$\leadsto$ case 20

$\multimap$ case 21

$-4$

Testing time

$\rightarrow$ case 22

$\multimap$ case 23

B

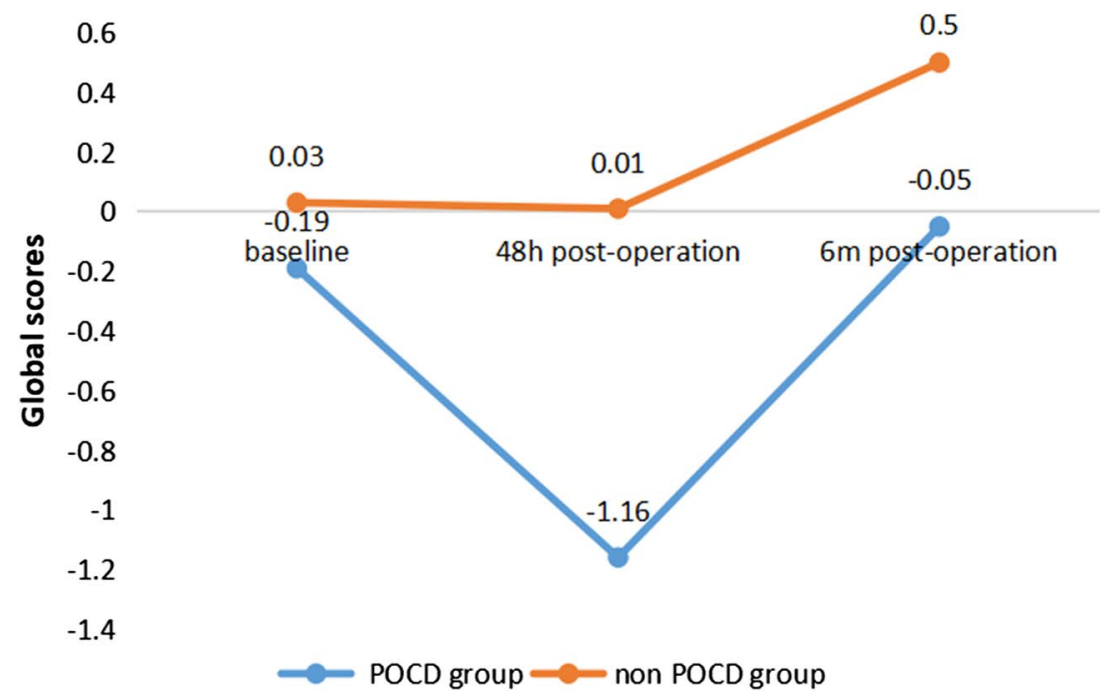

Fig. 3 Global cognitive scores. a The trajectories of global cognitive scores in patients with POCD at $48 \mathrm{~h}$ pose-operation. $\mathbf{b}$ The comparison between the POCD group and the non POCD group at baseline, $48 \mathrm{~h}$ post-ablation, 6 months post-ablation 
factors mentioned above, increased age, particular disease states might also be risk factors for POCD [29].

It has also been reported that left atrial access time is associated with POCD, as it may expose patients to a higher chance of incident brain lesion [5]. Intriguingly, the minimum intraoperative ACT values less than $300 \mathrm{~s}$ during the ablation procedure was found to be an independent risk factor for POCD, indicating that adequate anticoagulation during the procedure might exert an effect in preventing POCD. Several studies have found that more aggressive anticoagulation during ablation were associated with a lower risk of symptomatic embolic events [30,31] and a lower frequency of LA thrombus formation [32]. Regarding asymptomatic embolic events, studies have showed that lower intraprocedural ACT $[33,34]$ and increased procedure duration before systemic heparinization [35] were related with an increased risk of asymptomatic cerebral embolism (ACE), and that the presence of spontaneous echo contrast in the LA was also related with ACE risk $[35,36]$. These data suggested that well-controlled intraprocedural ACT and earlier heparinization may reduce the risk of ACE, as confirmed in a prospective, multicenter study [27].

Irregular anticoagulation prior to the ablation is also a POCD risk factor, even if no thrombosis was detected by pre-procedural esophageal ultrasound. Long-term anticoagulation might decrease potential thromboses in the left atrial appendage or left atrium that cannot be detected by esophageal ultrasound. The catheter operation in the left atrium and conversion to the sinus rhythm may cause these small clots to fall off and cause an asymptomatic embolism, thereby affecting the patient's cognitive function. Routine administration of oral anticoagulants for one month before ablation eliminated most of the tiny clots and thus might have the potential to reduce POCD. Moreover, the risk of thrombosis resulting from LMWH bridging should not be neglected. Previous studies have shown a $2 \%$ incidence of silent cerebral lesions in AF ablation patients under uninterrupted warfarin anticoagulation and a $14 \%$ in those with LMWH bridging [27]. In this study, the association of LMWH bridging with POCD was not observed, which was possibly due to that the small size of uninterrupted patients $(\mathrm{n}=27,14.2 \%)$ is not sufficient to illustrate the difference.

Emerging evidence has found that $\mathrm{AF}$ ablation improves long-term cognitive function, and this improvement begins to appear in the third month after ablation [10]. In the present study, cognitive improvement was also observed at the 6-month follow up, while the trajectories of each cognitive domain were further described.
Both clinically and statistically significant changes were observed in memory, executive function, working memory and processing function, verbal fluency test and visual-motor coordination, which conforms well to the cognitive domains that are most commonly impaired in AF patients [24, 37]. The recovery of sinus rhythm after AF ablation improves atrioventricular synchronization as well as the systolic and diastolic function [38], which may enhance cerebral perfusion, promoting the recovery and improvement of cognitive function.

Most POCD cases had a tendency of recovery at 6 months, consistent with a recent study, which reported that most acute brain lesions after ablation disappeared at 6 months post-ablation depending on the specific MRI [7].

Although the patients' cognitive function was carefully measured for POCD diagnosis, diffusion-weighted MRI were not performed before and after ablation. Therefore, the estimation accuracy of the true lesion rate and the impact of embolic events on the cognitive outcome may be affected. With the recent development and widespread usage of an uninterrupted perioperative NOAC strategy, a better anticoagulation strategy before and during the ablation procedure, the perioperative stroke/TIA rate may have been lowered, thus, the results may have overestimated the POCD rate.

\section{Conclusions}

Atrial fibrillation ablation is associated with a $13.7 \%$ prevalence of POCD within $48 \mathrm{~h}$ after ablation procedures. Patients, who were not on routine anticoagulants within one month prior to the ablation procedure and with a minimum intraoperative $\mathrm{ACT}$ value of less than $300 \mathrm{~s}$, were found to have a higher association with POCD events. The POCD is temporary in most patients, and a general improvement was observed in cognitive function at 6 months after the procedure. Further studies regarding the long-term effects of catheter ablation on patients' cognitive function are warranted for a more comprehensive understanding in this area.

\section{Appendix}

See Table 4 and Fig. 4. 
Table 4 Description of Neuropsychological Tests

\begin{tabular}{|c|c|c|}
\hline Test & Description & Cognitive domain \\
\hline $\begin{array}{l}\text { CERAD Auditory-Verbal } \\
\text { Learning Test-Immediate }\end{array}$ & $\begin{array}{l}\text { First, the patients were read ten words. Then, they were required to recall the } \\
\text { words as many as possible. This was repeated twice; yet, the word order was } \\
\text { changed every time. The maximum number of words correctly recalled was } \\
\text { recorded }\end{array}$ & Memory \\
\hline $\begin{array}{l}\text { CERAD Auditory-Verbal } \\
\text { Learning Test-Delayed }\end{array}$ & $\begin{array}{l}\text { After } 15 \text { min, the patients were required to recall as many as possible of the } \\
\text { ten words from the CERAD Auditory-Verbal Learning Test-Immediate with- } \\
\text { out rereading. The number of words correctly remembered was recorded }\end{array}$ & Memory \\
\hline Trail Making Task Part A & $\begin{array}{l}\text { Twenty-five circles numbered 1-25 distributed over a sheet of paper. The } \\
\text { patients were instructed to connect the circles by drawing lines with the } \\
\text { numbers in ascending order as fast as possible. The time spent to complete } \\
\text { the task was the score.to be recorded }\end{array}$ & Executive functioning \\
\hline Trail Making Task Part B & $\begin{array}{l}\text { Twenty-five circles were distributed over a sheet of paper; the circles included } \\
\text { either numbers }(1-13) \text { or letters (A-L). The patients were instructed to } \\
\text { connect the circles by drawing lines between the numbers and letters in } \\
\text { ascending order (i.e.,1-A-2-B-3-C, and so on). The time spent to complete } \\
\text { the task was recorded as the score }\end{array}$ & Executive functioning \\
\hline $\begin{array}{l}\text { Digit Symbol Substitution } \\
\text { Test }\end{array}$ & $\begin{array}{l}\text { The patients were required to reproduce coded symbols on paper as many as } \\
\text { possible within blank boxes beneath the digits randomly generated, based } \\
\text { on a coding scheme that paired the digits with symbols. The number of cor- } \\
\text { rect symbols reproduced within } 90 \text { s was recorded as the score }\end{array}$ & Memory and processing function \\
\hline $\begin{array}{l}\text { Controlled Oral Word } \\
\text { Association Test }\end{array}$ & $\begin{array}{l}\text { The patients were instructed to say words as many as possible within } 60 \text { s that } \\
\text { start with a given Chinese character component." } \forall, 1 \text {, and } 日 \text { " were tested }\end{array}$ & Verbal fluency test \\
\hline CERAD Semantic Fluency Test & $\begin{array}{l}\text { The patients were instructed to make a list of words as many as possible } \\
\text { within } 60 \text { secondsfrom a predefined category (fruits). The number of correct } \\
\text { answers was recorded }\end{array}$ & Verbal fluency test of semantic memory \\
\hline $\begin{array}{l}\text { Grooved Pegboard Test } \\
\text { (Dominant Hand) }\end{array}$ & $\begin{array}{l}\text { The patients were required to insert } 25 \text { keyed pegs into a pegboard which } \\
\text { was specially designed with randomly positioned slots. The pegs must } \\
\text { match the hole, or they cannot be inserted.The time spent to complete the } \\
\text { task was recorded }\end{array}$ & $\begin{array}{l}\text { Requires complex visual-motor coordi- } \\
\text { nation and evaluates the lateralized } \\
\text { injury }\end{array}$ \\
\hline $\begin{array}{l}\text { Grooved Pegboard Test } \\
\text { (Nondominant Hand) }\end{array}$ & $\begin{array}{l}\text { The patients completed the same task with the nondominant hand. The time } \\
\text { taken to complete the task was recorded }\end{array}$ & $\begin{array}{l}\text { Requires complex visual-motor coordi- } \\
\text { nation and evaluates the lateralized } \\
\text { injury }\end{array}$ \\
\hline
\end{tabular}

Adapted from Silbert et al. [13]

CERAD, the Consortium to Establish a Registry for Alzheimer's Disease

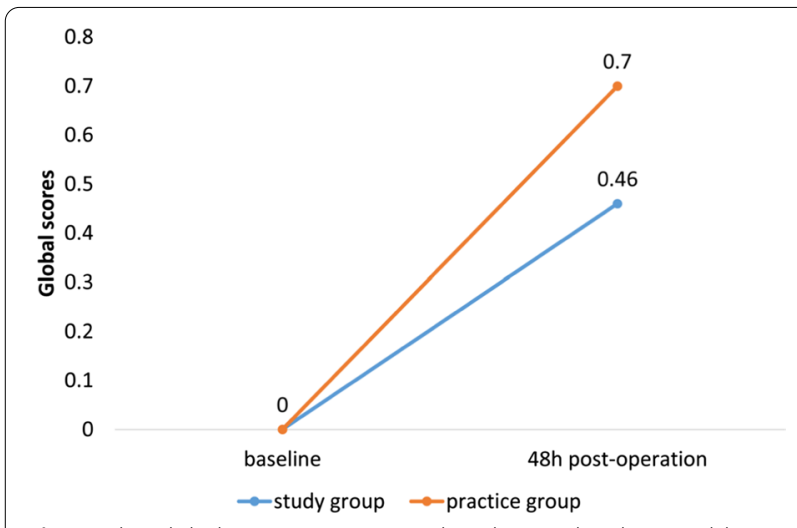

Fig. 4 The global cognitive scores at baseline and $48 \mathrm{~h}$ post ablation for the study group and the practice group

\section{Abbreviations}

AF: Atrial fibrillation; RCl: Reliable change index; POCD: Postoperative cognitive dysfunction; ACT: Activated clotting time; QoL: Quality of life; RCl: Reliable change index; TEE: Transesophageal echocardiography; INR: International normalized ratio; NOAC: New oral anticoagulants; PAF: Paroxysmal atrial fibrillation; SD: Standard deviation; MMSE: Mini-Mental State Examination.

\section{Acknowledgements}

Not applicable.

\section{Authors' contributions}

JZ was dedicated to the integrity of the entire study, study design, literature research, clinical and experimental studies, data acquisition and analysis, manuscript preparation; SJX focused on the definition of intellectual content, clinical studies, manuscript editing and manuscript review; XD was involved in the study design, data analysis and manuscript editing; CJ carried out the definition of intellectual content and manuscript review; YWL was dedicated to the literature research and manuscript preparation; YFW was dedicated to experimental studies and data acquisition; ZXJ was involved in the data analysis and statistical analysis; LH carried out the statistical analysis; RBT was involved in the manuscript editing. JZD was involved in the manuscript review; CSM was involved in the guarantor of integrity of the entire study, study concepts and design. All authors have read and approved this article. 


\section{Funding}

This study was supported by National Key Research and Development Program of China (2016YFC0900901, 2017YFC0908803).

\section{Availability of data and materials}

The datasets used and/or analyzed during the current study are available from the corresponding author on reasonable request.

\section{Declarations}

\section{Ethics approval and consent to participate}

All procedures performed in studies involving human participants were in accordance with the ethical standards of the institutional and/or national research committee and with the 1964 Helsinki declaration and its later amendments or comparable ethical standards. This study is approved by Ethics Committee of Beijing Anzhen Hospital (D11110700300000). Informed consent was obtained from all individual participants included in the study.

\section{Competing interests}

The author declare that they have no competing interest.

\section{Author details}

${ }^{1}$ Department of Cardiology, Beijing Anzhen Hospital, Capital Medical University, National Clinical Research Center for Cardiovascular Diseases, No. 2 Anzhen Road, Chaoyang District, Beijing 100029, China. ${ }^{2}$ Department of Cardiology, Affiliated Hospital of Hebei University, Baoding 071000, China.

Received: 2 December 2020 Accepted: 24 June 2021

Published online: 14 July 2021

\section{References}

1. Calkins H, Reynolds MR, Spector P, et al. Treatment of atrial fibrillation with antiarrhythmic drugs or radiofrequency ablation: two systematic literature reviews and meta-analyses. Circ Arrhythm Electrophysiol. 2009;2(4):349-61.

2. Morillo CA, Verma A, Connolly SJ, et al. Radiofrequency ablation vs antiarrhythmic drugs as first-line treatment of paroxysmal atrial fibrillation (RAAFT-2): a randomized trial. JAMA. 2014;311(7):692-700.

3. Wazni OM, Marrouche NF, Martin DO, et al. Radiofrequency ablation vs antiarrhythmic drugs as first-line treatment of symptomatic atrial fibrillation: a randomized trial. JAMA. 2005;293(21):2634-40.

4. Conen D, Rodondi N, Muller A, et al. Relationships of overt and silent brain lesions with cognitive function in patients with atrial fibrillation. J Am Coll Cardiol. 2019;73(9):989-99.

5. Medi C, Evered L, Silbert B, et al. Subtle post-procedural cognitive dysfunction after atrial fibrillation ablation. J Am Coll Cardiol. 2013;62(6):531-9.

6. Haeusler KG, Koch L, Herm J, et al. 3 Tesla MRI-detected brain lesions after pulmonary vein isolation for atrial fibrillation: results of the MACPAF study. J Cardiovasc Electrophysiol. 2013;24(1):14-21.

7. Herm J, Fiebach JB, Koch L, et al. Neuropsychological effects of MRIdetected brain lesions after left atrial catheter ablation for atrial fibrillation: long-term results of the MACPAF study. Circ Arrhythm Electrophysiol. 2013;6(5):843-50.

8. Von Bary C, Deneke T, Arentz T, et al. Silent cerebral events as a result of left atrial catheter ablation do not cause neuropsychological sequelae-a MRI-controlled multicenter study. J Interv Card Electrophysiol. 2015;43(3):217-26.

9. Schwarz N, Kuniss M, Nedelmann M, et al. Neuropsychological decline after catheter ablation of atrial fibrillation. Heart Rhythm. 2010;7(12):1761-7.

10. Jin MN, Kim TH, Kang KW, et al. Response by Jin et al to Letter Regarding Article, "Atrial fibrillation catheter ablation improves 1-year follow-up cognitive function, especially in patients with impaired cognitive function." Circ Arrhythm Electrophysiol. 2019;12(10):e007880.

11. Canadian study of health and aging: study methods and prevalence of dementia. Cmaj, 1994, 150(6): 899-913.
12. Evered LA, Silbert BS, Scott DA, et al. Plasma amyloid beta42 and amyloid beta40 levels are associated with early cognitive dysfunction after cardiac surgery. Ann Thorac Surg. 2009;88(5):1426-32.

13. Silbert BS, Scott DA, Evered LA, et al. A comparison of the effect of highand low-dose fentanyl on the incidence of postoperative cognitive dysfunction after coronary artery bypass surgery in the elderly. Anesthesiology. 2006;104(6):1137-45

14. Evered LA, Silbert BS, Scott DA. Postoperative cognitive dysfunction and aortic atheroma. Ann Thorac Surg. 2010;89(4):1091-7.

15. Evered LA, Silbert BS, Scott DA, et al. Preexisting cognitive impairment and mild cognitive impairment in subjects presenting for total hip joint replacement. Anesthesiology. 2011;114(6):1297-304.

16. Rasmussen LS, Larsen $K$, Houx $P$, et al. The assessment of postoperative cognitive function. Acta Anaesthesiol Scand. 2001;45(3):275-89.

17. Singh-Manoux A, Fayosse A, Sabia S, et al. Atrial fibrillation as a risk factor for cognitive decline and dementia. Eur Heart J. 2017;38(34):2612-8.

18. Medi C, Sparks PB, Morton JB, et al. Pulmonary vein antral isolation for paroxysmal atrial fibrillation: results from long-term follow-up. J Cardiovasc Electrophysiol. 2011;22(2):137-41.

19. Rosso R, Sparks PB, Morton JB, et al. Vagal paroxysmal atrial fibrillation: prevalence and ablation outcome in patients without structural heart disease. J Cardiovasc Electrophysiol. 2010;21(5):489-93.

20. Dong JZ, Sang $\mathrm{CH}$, Yu RH, et al. Prospective randomized comparison between a fixed "2C3L" approach vs. stepwise approach for catheter ablation of persistent atrial fibrillation. Europace. 2015;17(12):1798-806.

21. Vermeer SE, Longstreth WT Jr, Koudstaal PJ. Silent brain infarcts: a systematic review. Lancet Neurol. 2007;6(7):611-9.

22. Atanassova PA, Massaldjieva RI, Dimitrov BD, et al. Early neurological and cognitive impairments in subclinical cerebrovascular disease. Neurol India. 2016;64(4):646-55.

23. Blum S, Luchsinger JA, Manly JJ, et al. Memory after silent stroke: hippocampus and infarcts both matter. Neurology. 2012;78(1):38-46.

24. Gaita F, Corsinovi L, Anselmino M, et al. Prevalence of silent cerebral ischemia in paroxysmal and persistent atrial fibrillation and correlation with cognitive function. J Am Coll Cardiol. 2013;62(21):1990-7.

25. Deneke T, Jais P, Scaglione M, et al. Silent cerebral events/lesions related to atrial fibrillation ablation: a clinical review. J Cardiovasc Electrophysiol. 2015:26(4):455-63.

26. Haeusler KG, Kirchhof P, Endres M. Left atrial catheter ablation and ischemic stroke. Stroke. 2012;43(1):265-70.

27. Di Biase L, Gaita F, Toso E, et al. Does periprocedural anticoagulation management of atrial fibrillation affect the prevalence of silent thromboembolic lesion detected by diffusion cerebral magnetic resonance imaging in patients undergoing radiofrequency atrial fibrillation ablation with open irrigated catheters? Results from a prospective multicenter study. Heart Rhythm. 2014;11(5):791-8.

28. Zhao $Y$, Yang $Y$, Tang $X$, et al. New oral anticoagulants compared to warfarin for perioperative anticoagulation in patients undergoing atrial fibrillation catheter ablation: a meta-analysis of continuous or interrupted new oral anticoagulants during ablation compared to interrupted or continuous warfarin. J Interv Card Electrophysiol. 2017;48(3):267-82.

29. Kotekar N, Shenkar A, Nagaraj R. Postoperative cognitive dysfunction current preventive strategies. Clin Interv Aging. 2018;13:2267-73.

30. Di Biase L, Burkhardt JD, Mohanty P, et al. Periprocedural stroke and management of major bleeding complications in patients undergoing catheter ablation of atrial fibrillation: the impact of periprocedural therapeutic international normalized ratio. Circulation. 2010;121(23):2550-6.

31. Wazni OM, Rossillo A, Marrouche NF, et al. Embolic events and char formation during pulmonary vein isolation in patients with atrial fibrillation: impact of different anticoagulation regimens and importance of intracardiac echo imaging. J Cardiovasc Electrophysiol. 2005;16(6):576-81.

32. Ren JF, Marchlinski FE, Callans DJ, et al. Increased intensity of anticoagulation may reduce risk of thrombus during atrial fibrillation ablation procedures in patients with spontaneous echo contrast. J Cardiovasc Electrophysiol. 2005;16(5):474-7.

33. Gaita F, Caponi D, Pianelli M, et al. Radiofrequency catheter ablation of atrial fibrillation: a cause of silent thromboembolism? Magnetic resonance imaging assessment of cerebral thromboembolism in patients undergoing ablation of atrial fibrillation. Circulation. 2010;122(17):1667-73. 
34. Scaglione M, Blandino A, Raimondo C, et al. Impact of ablation catheter irrigation design on silent cerebral embolism after radiofrequency catheter ablation of atrial fibrillation: results from a pilot study. J Cardiovasc Electrophysiol. 2012;23(8):801-5.

35. Sakamoto T, Kumagai K, Nishiuchi $S$, et al. Predictors of asymptomatic cerebral infarction associated with radiofrequency catheter ablation for atrial fibrillation using an irrigated-tip catheter. Europace. 2013;15(3):332-8.

36. Martinek M, Sigmund E, Lemes $C$, et al. Asymptomatic cerebral lesions during pulmonary vein isolation under uninterrupted oral anticoagulation. Europace. 2013;15(3):325-31.

37. Nishtala A, Piers RJ, Himali JJ, et al. Atrial fibrillation and cognitive decline in the Framingham Heart Study. Heart Rhythm. 2018;15(2):166-72.
38. Cha YM, Wokhlu A, Asirvatham SJ, et al. Success of ablation for atrial fibrillation in isolated left ventricular diastolic dysfunction: a comparison to systolic dysfunction and normal ventricular function. Circ Arrhythm Electrophysiol. 2011;4(5):724-32.

\section{Publisher's Note}

Springer Nature remains neutral with regard to jurisdictional claims in published maps and institutional affiliations. 